\title{
Engaging with clinicians to implement and evaluate the ICF in neurorehabilitation practice
}

\section{Stephanie Tempest and Richard Jefferson}

Dr Stephanie Tempest PhD MSc BSc (Hons): Lecturer in Occupational Therapy, Brunel University, UK stephanie.tempest@brunel.ac.uk

Mr Richard Jefferson MSc, DipCOT, PGCE, Social Rehabilitation Manager, Headway SELNWK, London SE2 OAY. srm@headwayselnwk.co.uk

\begin{abstract}
Although deemed a globally accepted framework, there remains scare evidence on the process and outcome of implementing the International Classification of Functioning, Disability and Health (ICF) within neurorehabilitation. This review briefly explores the existing, broader literature then reports on two action research projects, undertaken in England, specifically within stroke and neurorehabilitation. Working with participants, including clinicians from in-patient and community settings, patients and their families, there are now 35 different ways identified for the use of the ICF. The outcome of the first project highlights that using the ICF enhances communication within and beyond the acute stroke service; fosters holistic thinking and clarifies team roles. To adopt it into practice, the ICF must be adapted to meet local service needs. The use of action research has facilitated the knowledge translation process which has enabled the ICF to become a clinical reality in neurorehabilitation.
\end{abstract}

\section{Background}

The International Classification of Functioning, Disability and Health (ICF: World Health Organisation [WHO], 2001) has been endorsed for use by multidisciplinary teams to aid communication within stroke care (Intercollegiate Stroke Working Party [ISWP], 2012) although endorsement does not necessarily guarantee its use within the clinical setting. Yet, the success of the ICF depends on its uptake in clinical practice (Geyh et al., 2004). A procedural manual and guide for standardised application of the ICF has been developed to assist practitioners (WHO, 2013), but 
this process has identified problematic areas within the ICF; in particular, the overlap of some of the codes and qualifiers as well as difficulties distinguishing between activities and participation (Reed et al., 2005).

A comprehensive literature review in 2009 concluded that the ICF was a globally accepted framework (Jelsma, 2009), yet the majority of the articles in the review focused on explaining the conceptual framework or applying it to the management of data collection, rather than using it in clinical practice with healthcare professionals and multidisciplinary teams. In 2011, a systematic review also concluded the majority of the 670 ICF papers examined were conceptual in nature (Cerniauskaite et al., 2011). Nonetheless, 173 papers focused on using it in clinical practice but these were mainly anecdotal reflections, or applying it in theory. The main conclusions from the clinically focused papers were that the ICF has the potential to improve team communication (e.g. Rentsch et al., 2003; Steiner et al., 2002); enhance interagency communication (e.g Martinuzzi et al., 2008; Darzins, Fone and Darzins, 2006); help clinicians construct a broader view of disability (e.g. O'Donovan, Doyle and Gallagher, 2009; Raggi, Leonardi, Cabello and Bickenback, 2010) and clarify team roles (Tempest and McIntyre, 2006; Mitchell, 2008).

None of the papers from the two reviews engaged, in a systematic manner, with neurorehabilitation clinicians in order to identify the process and outcome of the implementation process. Yet, clinicians still need to be convinced of the worth of investing time and finances into adopting the ICF into practice (Farrell, Anderson, Hewitt, Livingston and Stewart, 2007) partly, as they may lack in-depth knowledge and experience in using the framework (Farrell et al. 2007; Heinen, van Achterberg, Roodbol and Frederiks, 2005).

Empirical evidence regarding the process of implementing the ICF in practice is scarce (Verhoef, Toussaint, Putter, Zwetsloot-Schonk and Vliet Vlieland, 2008). Explicit use of change management theory has been suggested (Appleby and Tempest, 2006) and training programmes have been established, which are considered an effective way to teach health and social care professionals about the ICF (Francescutti, Martinuzzi, Leonardi and Kostanjsek, 2009; Bjorck-Akesson et al., 2010). However, the challenge of understanding the benefits of training is that it 
remains unclear if the ICF subsequently transfers into the clinical setting (Francescutti et al., 2009).

There is also scarce empirical evidence on the outcome of implementing the ICF into clinical practice. However, a study of two multidisciplinary teams in rheumatology (Verhoef et al., 2008) concluded that health care professionals held mixed opinions on the benefit of the implementation of the ICF. While staff satisfaction with team conferences increased in a day-patient setting, this effect was absent with staff in an inpatient setting. This study offers an insight, into staff perceptions, on the use of the ICF in clinical practice but, as the data was quantitative in nature, it is not known why staff held these opinions. Furthermore, the opinions from patients, carers and those beyond the multidisciplinary teams were not sought and these could have enhanced a fuller understanding of the outcomes. The research team concluded that the outcome of introducing ICF-based tools should be studied at the level of individual teams, to gain a greater understanding of the effects of using it in practice (Verhoef et al., 2008).

Therefore, despite the general endorsement and acknowledgement of the potential use of the ICF in clinical practice (Cerniauskaite et al., 2011) there has been no systematic attempt to explain or evaluate the means by which it can be implemented. There has been only one paper (Verhoef et al., 2008), using quantitative data to measure the outcome of so doing, which sought to assess staff satisfaction with the ICF, however this was in the field of rheumatology and not neurorehabilitation. These were some of the drivers for the body of action research currently being undertaken in England.

\section{Using action research to evaluate the process and outcome of implementing the ICF within neurorehabilitation in England.}

The first action research project, working with participants from one acute stroke team and its associated stakeholders, identified 15 different ways the ICF would benefit their service (detailed in Tempest, Harries, Kilbride, and De Souza, 2013). They chose to focus on developing an ICF-based transfer of care report, with an ICF glossary (using the detail from the core set for stroke) to aid its completion. On reviewing the outcome from the project, it was concluded that the use of the ICF 
enhanced communication within and beyond the stroke team; aided holistic thinking and helped to clarify team roles (Tempest et al 2013). However, in order to implement it into practice, the participants (including the multidisciplinary stroke team; patients; their families; and community neurorehabilitation colleagues) needed to adapt some of the language and adopt it in a way that met their local needs (Tempest, Harries, Kilbride and De Souza, 2012). To clarify, because the ICF is endorsed by the WHO and the National Clinical Guidelines for Stroke (ISWP 2012) it became a vehicle to drive through a change previously desired, i.e. a transfer of care report, which had not been formerly achieved by the participants.

On reflecting upon the experience, participants in the first project shared their experiences in the form of recommendations for others wanting to implement the ICF (see Table 1).

\section{INSERT TABLE 1 HERE}

On sharing the experiences a second project was developed, this time, with participants in a different community neurorehabilitation team. Working with the same action research approach (see Tempest et al 2012), the second author of this paper worked with participants to review the 15 original suggestions and identify additional ways to implement the ICF within neurorehabilitation. This resulted in an overall total of 35 possible ways to utilise the ICF, within this field (see Table 2).

\section{INSERT TABLE 2 HERE}

Many of these ideas reasonate with those postulated in the literature. The key point here is that these ideas have been identified by those working specifically within neurorehabilitation and, in so doing, the action research approach has enabled them to learn more about the potential for the ICF while implementing it at the same time.

Following the process of exploring potential uses for the ICF, the participants in the second project selected its use 'to explore using the ICF for clinical reasoning within an interprofessional team'. Full analysis of the data from the second action research project is currently underway although preliminary findings suggest a pragmatic 
approach to its use, dependent on factors such as: the complexity of the patient; the (perceived) demands on the team or individual clinician; the clinicians depth of knowledge (of the ICF) and; the perceived complexity of the ICF. These impressions broadly reflect those expressed by Farrell et al. (2007).

\section{Conclusion and clinical implications}

The evidence on the process and outcome of implementing the ICF within neurorehabilitation practice is scare. Now there are 35 different ways, identified by neurorehabilitation clinicians, for the potential use of the ICF in clinical practice. The implications for practice are that: 1) using an action research approach offers support for clinicians to learn and think about the ICF whilst implementing it at the same time; 2) clinicians, working in neurorehabilitation, can identify many ways for the uptake of the ICF into their practice; and 3) reflecting on the process of ICF implementation, there are now recommendations and pragmatic suggestions for other neurorehabilitation teams wanting to do the same.

Finally, when identifying the key learning from the outcome of developing ICF based clinical tools, it has been determined that the ICF enhances clarity and holism and aids holistic thinking. But in order to adopt the theory into practice it must be adapted to meet the local service needs. Using an action research approach has enabled the theoretical framework and classification to become a clinical reality within neurorehabilitation.

\section{Future research}

The first two projects detailed here explored the use of the ICF to develop a transfer of care report and a clinical reasoning tool. Future research could explore the process and outcome of implementing the ICF for the other ways identified in Table Two. Both projects involved one action researcher working with one team at a time, thereby resource intensive. Future action research projects could explore the effectiveness of different models of practice including facilitating a number of teams who work and explore the issues together across different clinical settings. 


\section{References}

Appleby, H., \& Tempest, S. (2006). Using change management theory to implement the International Classification of Functioning, Disability and Health (ICF) in clinical practice. British Journal of Occupational Therapy 69(10) 477-480. Retrieved from http://www.ingentaconnect.com/content/cot/bjot/

Bjorck-Akesson, E., Wilder, J., Granlund, M., Pless, M., Simeonsoon, R., Adolfsson, M., ... Lilvist, A. (2010). The International Classification of Functioning, Disability and Health and the version for children and youth as a tool in child habilitation / early childhood intervention - feasibility and usefulness as a common language and frame of reference for practice. Disability and Rehabilitation 32(S1) pp. S125-S138. doi: 10.3109/09638288.2010.516787

Cerniauskaite, M., Quintas, R., Boldt, C., Raggi, A., Cieza, A., Bickenback, J. \& Leonardi, M. (2011). Systematic review on ICF from 2001-2009: its use, implementation and operationalization. Disability and Rehabilitation 33(4) pp. 281309. doi: 10.3109/09638288.2010.529235

Darzins, P., Fone, S. \& Darzins, S. (2006). The International Classification of Functioning, Disability and Health can help to structure and evaluate therapy. Australian Occupational Therapy Journal: 53 (2) pp. 127-131. Retrieved from http://onlinelibrary.wiley.com/journal/10.1111/(ISSN)1440-1630

Farrell, J., Anderson, S., Hewitt, K., Livingston, M. \& Stewart, D. (2007). A survey of occupational therapists in Canada about their knowledge and use of the ICF. Canadian Journal of Occupational Therapy, 74 (Special Issue) pp.221-232. Retrieved from http://cjo.sagepub.com/

Francescutti, C., Martinuzzi, A., Leonardi, M. \& Kostanjsek, N. (2009). Eight years of ICF in Italy: Principles, results and future perspectives. Disability and Rehabilitation 31(S1) pp. S4-S7. doi: 10.3109/09638280903317898.

Geyh, S., Cieza, A., Schouten, J., Dickson, H., Dommelt, P., Omar, Z., ... Stucki, G. (2004). ICF core sets for stroke. Journal of Rehabilitation Medicine Supplement 44 pp.135-141. Retrieved from http://www.medicaljournals.se/jrm/content/?volume=36\&issue=44

Heinen, M., van Achterberg, T., Roodbol, G. \& Frederiks, C. (2005). Applying ICF in nursing practice: classifying elements of nursing diagnoses. International Nursing Review 52 (4) pp.304-312. Retrieved from http://onlinelibrary.wiley.com/doi/10.1111/inr.2005.52.issue-4/issuetoc

Intercollegiate Stroke Working Party. (2012). National Clinical Guidelines for Stroke 4th edition. Royal College of Physicians. London.

Jelsma, J. (2009). Use of the International Classification of functioning, Disability and Health: a literature survey. Journal of Rehabilitation Medicine 41 (1) pp.1-12. doi: 10.2340/16501977-0300 
Martinuzzi, A., Frare, M., Pradal, M., Mion, M., Dugone, S., Durante, M., ... Leonardi, M. (2008). Disseminating the WHO International Classification of Functioning, Health and Disability (ICF) in the Veneto Region of Italy. Disability and Rehabilitation 30(1) pp. 71-80. doi:10.1080/09638280701191792

Mitchell, L. (2008). Can the International Classification of Functioning, Disability and Health (ICF) provide high-level descriptions of Scottish physiotherapy cases? Advances in Physiotherapy 10 (3) pp.119-126. doi:10.1080/14038190802180204

O'Donovan, M., Doyle, A. \& Gallagher, P. (2009). Barriers, activities and participation: incorporating ICF into service planning datasets. Disability and Rehabilitation 31(25) pp. 2073-2080. Retrieved from http://informahealthcare.com/loi/doi/abs/10.3109/09638280902918738

Raggi, A., Leonardi, M., Cabello, M., \& Bickenback JE. (2010). Editorial: Application of ICF in clinical settings across Europe. Disability and Rehabilitation 32(S1) pp. S17-S22. doi:10.3109/09638288.2010.511692

Reed, G., Leonardi, M., Syuso-Mateos, J., Materzanini, A., Castronuovo, D., Manara, A., ... Ajovalasit, D. (2009). Implementing the ICF in a psychiatric rehabilitation setting for people with serious mental illness in the Lombardy region of Italy. Disability and Rehabilitation 31(S1) pp. S170-S173. Retrieved from http://informahealthcare.com/loi/doi/abs/10.3109/09638280903317955

Rentsch, H., Bucher, P., Dommen Nyffeler, I., Wolf, C., Hefti, H., Fluri, E., ... Boyer, I. (2003). The implementation of the International Classification of Functioning Disability and Health (ICF) in daily practice of neurorehabilitation: an interdisciplinary project at the Kantonsspital of Lucerne, Switzerland. Disability and Rehabilitation 25(8) pp. 411-421. doi:10.1080/0963828031000069717

Steiner, W., Ryser, L., Huber, E., Uebelhart, D., Aeschlimann, A. \& Stucki, G. (2002). Use of the ICF model as a clinical problem-solving tool in physical therapy and rehabilitation medicine. Physical Therapy 82(11) pp. 1098-1107. Retrieved from http://ptjournal.apta.org/content/82/11/1098.full?sid=fbef0d7b-062a-4230-80549cb13c3dc9ee

Tempest, S. and Mclntyre, A. (2006). Using the ICF to clarify team roles and demonstrate clinical reasoning in stroke rehabilitation. Disability and Rehabilitation 28 (10) pp. 663 -667. doi:10.1080/09638280500276992

Tempest, S., Harries, P., Kilbride, C., \& De Souza, L. (2012). To adopt is to adapt: The process of implementing the ICF with an acute stroke multidisciplinary team in England. Disability and Rehabilitation 34 (20) pp.1686-1694. doi: 10.3109/09638288.2012.658489

Tempest, S., Harries, P., Kilbride, C. \& De Souza, L. (2013). Enhanced clarity and holism: The outcome of implementing the ICF with an acute stroke multidisciplinary team in England. Disability and Rehabilitation 35 (22) pp. 1921- 1925.

doi: 10.3109/09638288.2013.766272 
Verhoef, J., Toussaint, P., Putter, H., Zwetsloot-Schonk, J. \& Vliet Vlieland, T. (2008). The impact of introducing an ICF-based rehabilitation tool on staff satisfaction with multidisciplinary team care in rheumatology: an exploratory study. Clinical Rehabilitation 22 (1) pp. 23-37. doi:10.1177/0269215507079845

World Health Organisation. (2001). The International Classification of Functioning, Disability and Health (ICF). WHO Geneva

World Health Organisation .(2013). How to use the ICF. A Practical Manual for using the International Classification of Functioning, Disability and Health (ICF) Exposure draft for comment. Geneva. WHO.

http://www.who.int/classifications/drafticfpracticalmanual2.pdf?ua=1 
Table 1. Recommendations for other people wanting to introduce the ICF into their own clinical setting from the reflective focus group and interviews

Be prepared to pilot, pilot, pilot!

Don't worry about just having a go - you can change things from doing this.

Pick projects that are practical and the majority of people would like to change in your team.

Have one person to facilitate the project, e.g. a stroke coordinator, although an external person is better as they avoid the day to day politics and often see something with fresh eyes.

Be prepared that the project will take time.

Share what you are doing with everyone in the team - even if they don't want a big role. Share what you are doing with people outside of the team - external feedback is useful and can also be motivating and nice.

Expect peaks and troughs throughout the project.

Don't give up if you run into problems - find a way around them.

At the start, do a team analysis of the potential driving forces and restraining forces that may occur during the project - embrace the positives and think about ways to manage the negatives. 


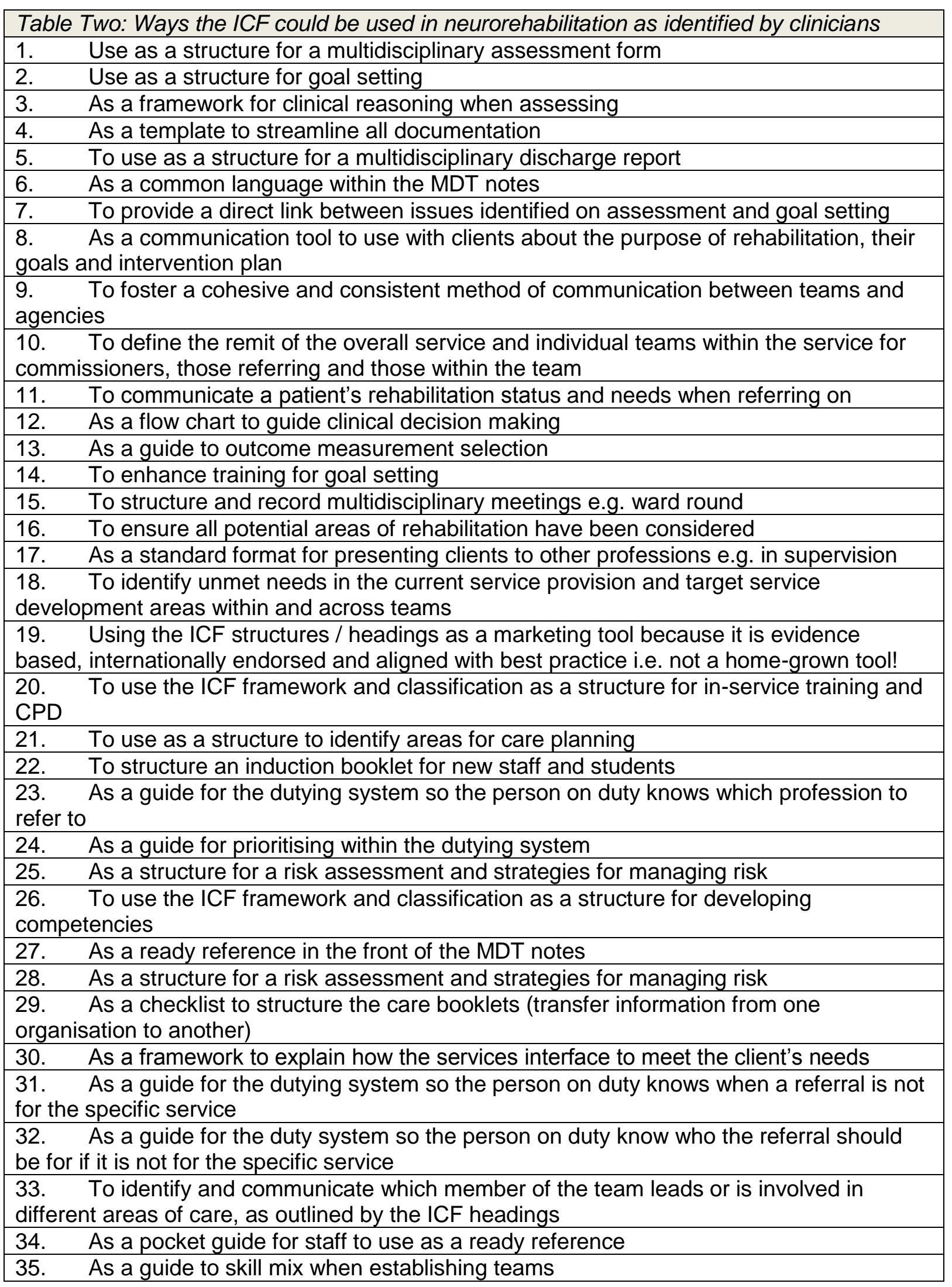

